\title{
Maternal and neonatal outcomes in covid negative and covid probable obstetric women presenting with covid like symptoms
}

\author{
Bhanu Priya, Sandhya Jain, AG Radhika, Mahendra Kumar, Amita Suneja, Sushil Srivastava \\ Corresponding author: Dr. Sandhya Jain, Professor, Department of Obstetrics and Gynaecology, \\ University College of Medical Sciences and Guru Teg Bahadur Hospital, Delhi, India; \\ Email : drsandy2015@gmail.com
}

Distributed under Attribution-Non Commercial - Share Alike 4.0 International (CC BY-NC-SA 4.0)

\section{ABSTRACT}

\begin{abstract}
Objective: To study maternal and neonatal outcomes in covid negative and covid probable with covid like symptoms. Method: It was a retrospective study conducted in obstetrics and gynaecology department of Guru Teg Bahadur Hospital and University College of Medical Sciences, Delhi, India. Case records of 130 pregnant, postpartum or postabortal women admitted with covid like symptoms were analyzed and categorized into covid negative (CN), positive $(\mathrm{CP})$ or probable (CPro), based on RT-PCR report. The main outcome measures were disease categorization, pregnancy complications, maternal mortality and neonatal outcomes in the three groups. Results: Majority of the women were CN (76\%), followed by CP (16.9\%) and C Pro (6.9\%). In all groups, mild disease was most common and severe disease was present in $18.1 \%, 13.6 \%$ and $33.3 \%$ in $\mathrm{CN}, \mathrm{CP}$ and CPro groups respectively. The spectrum of maternal disease in the study groups ranged from isolated febrile illness to multi-organ dysfunction (MODS). The frequency of women requiring oxygen, mechanical ventilation and intensive care unit was more in CPro group. Overall, there were 21(16.1\%) maternal deaths. Sepsis with MODS was the commonest cause of death in CN group, whereas, it was ARDS in CP and CPro groups. Stillbirths were more often seen in CPro group. Conclusion: Threefourth of admitted women were covid negative. A small subset was labelled as covid probable due to inconclusive or no testing. This group had the highest morbidity and mortality. Prompt testing and initiation of treatment could have redefined the disease course in covid probable group.
\end{abstract}

Keywords: Covid suspect, obstetric women, covid negative, covid probable, covid positive.

The outbreak of covid-19 infection, which started in December 2019, has become a global public health emergency. India reported its first case in January end, in the southern state of Kerala. Data on the impact of covid on the maternal and neonatal outcome is under extensive research and several systematic reviews and meta-analysis are already available. $^{1,2}$ Because of the ongoing pandemic, the main focus of research has been on covid confirmed cases; however, there were many non covid or probable cases admitted during this time, who did not receive much attention. Due to the protean presentations of covid illness, WHO has introduced definitions for clarity of management. ${ }^{3}$
The covid positive case is defined as a laboratory confirmed case of covid 19 infection irrespective of clinical signs and symptoms. The probable case is a suspect case for whom testing for the covid19 virus is inconclusive or could not be performed for any reason.

The differentiation between clinical features of covid positive, negative and probable patients is difficult. Covid19 infection in obstetric women may have variable presentations. Its clinical manifestations range from cough, fever and can progress from influenza like illness (ILI) to acute respiratory distress syndrome (ARDS) and occasionally death. Various non-covid conditions e.g. sepsis

Received: $28^{\text {th }}$ February 2021, Peer review completed: $24^{\text {th }}$ April 2021, Accepted: $1^{\text {st }}$ May 2021.

Priya B, Jain S, Radhika AG, Kumar M, Suneja A, Srivastava S. Maternal and neonatal outcomes in covid negative and covid probable obstetric women presenting with covid like symptoms. The New Indian Journal of OBGYN. 2021; 8(1): $75-80$. 
The New Indian Journal of OBGYN. 2021 (July-December);8(1)

with multi organ dysfunction (MODS), pulmonary oedema or tuberculosis may mimic covid disease. Despite similarity in clinical presentations, the outcome may be different for this condition. To the best of our knowledge, there is no study on covid negative and covid probable obstetric women so far. Therefore, the main objective of the present research was to study and compare the maternal - neonatal outcomes of covid negative and covid probable with covid positive obstetric women.

\section{Materials and methods}

We conducted a retrospective study in the department of obstetrics and gynaecology of a tertiary care hospital, in New Delhi, India from 1st April 2020 to $10^{\text {th }}$ June 2020. All antenatal, postnatal \& post-abortal women upto 6 weeks, admitted as covid suspect during this time were included. The study protocol was approved by institutional ethical committee. As it was a pilot study, sample size calculation was not done and all obstetric women admitted as covid negative, positive or probable cases were included. The data was extracted from the hospital records and women whose data was irretrievable from the medical record department were excluded from the study. No funding was required for the study.

After admission, covid suspect obstetric patients underwent reverse transcriptase -polymerase chain reaction test (RT-PCR) for severe acute respiratory syndrome coronavirus 2 (SARSCoV-2) by nasopharyngeal swab. They were divided into covid negative $(\mathrm{CN})$, covid probable (CPro) or covid positive (CP) based on the test report and were managed as per the hospital policy. Information was recorded in a pre-designed questionnaire. Women were categorized into mild/moderate/severe disease according to the WHO guidelines. ${ }^{3}$ Various outcome measures were prevalence of disease categorization at admission, pregnancy complications, maternal mortality and neonatal outcomes in the study groups.

Parametric and nonparametric descriptive statistics were used to examine the different groups. Student t-test was used to compare groups for continuously distributed data;
Wilcoxon test was applied for non-normally distributed data. Chi-square test, Mann Whitney test were used to compare categorical variables. Fisher's exact test was used where frequency in the contingency table was less than five for $>25 \%$ of cells. The nonparametric test (Kruskal Wallis Test) was used to make intergroup comparisons. $\mathrm{P}$ value $<0.05$ was taken as significant and SPSS 23 was used for analysis.

\section{Results and observations}

A total of 130 covid suspect obstetric women, admitted from $1^{\text {st }}$ April to $10^{\text {th }}$ June2020, were recruited for the study.

\begin{tabular}{|c|c|c|c|c|c|}
\hline Parameters & $\begin{array}{l}\text { Total } \\
n=130(\%)\end{array}$ & $\begin{array}{l}\mathrm{CN} \\
\mathrm{n}=99(\%)\end{array}$ & $\begin{array}{l}\mathrm{CP} \\
n=22(\%)\end{array}$ & $\begin{array}{l}\text { CPro } \\
n=9(\%)\end{array}$ & $\begin{array}{l}P \\
\text { value }\end{array}$ \\
\hline Mean age (SD) in years & $26.14 \pm 4.97$ & $26.45 \pm 4.83$ & $24.73 \pm 5.09$ & $28.45 \pm 9.16$ & 0.236 \\
\hline \multicolumn{6}{|l|}{ Socio-economic status } \\
\hline Upper lower & $40(30.7)$ & $31(31.3)$ & $6(27.3)$ & $3(33.3)$ & \multirow{3}{*}{0.894} \\
\hline Lower middle & $53(40.7)$ & $39(39.3)$ & $11(50)$ & $3(33.3)$ & \\
\hline$>$ Upper middle & $37(28.4)$ & $29(29.3$ & $5(22.7)$ & $3(33.3)$ & \\
\hline \multicolumn{6}{|l|}{ Education } \\
\hline Primary & $31(23.8)$ & $26(26.3)$ & $4(18.1)$ & $1(11.11)$ & \multirow{3}{*}{0.662} \\
\hline Senior secondary & $74(56.9)$ & $54(54.5)$ & $13(59.1)$ & $7(77.7)$ & \\
\hline Graduate/ above & $25(19.2)$ & $19(19.2)$ & $5(22.7)$ & $1(11.11)$ & \\
\hline \multicolumn{6}{|l|}{ Religion } \\
\hline Hindu & $72(55.3)$ & $53(53.5)$ & $11(50)$ & $4(44.4)$ & \multirow{3}{*}{0.735} \\
\hline Muslim & $46(35.3)$ & $36(36.3)$ & $7(31.8)$ & $3(33.3)$ & \\
\hline Others & $12(9.2)$ & $10(10.01)$ & $4(18.1)$ & $2(22.2)$ & \\
\hline Antenatal & $79(60.7)$ & $59(59.5)$ & $16(72.72)$ & $4(44.4)$ & \multirow{4}{*}{0.205} \\
\hline $1^{\text {st }}$ trimester & $2(1.53)$ & $2(2.1)$ & 0 & 0 & \\
\hline $2^{\text {nd }}$ trimester & $4(3.1)$ & $3(3.1)$ & $1(4.5)$ & 0 & \\
\hline $3^{\text {rd }}$ trimester & $73(56.1)$ & $54(54.5)$ & $15(68.2)$ & $4(44.4)$ & \\
\hline Postnatal & $41(31.5)$ & $31(31.3)$ & $6(27.27)$ & $4(44.4)$ & 0.643 \\
\hline Post-abortal (<6 weeks) & $10(7.6)$ & $9(9.09)$ & 0 & $1(11.1)$ & 0.570 \\
\hline \multicolumn{6}{|l|}{ Comorbidities } \\
\hline Anaemia & $25(19.2)$ & 19(19.2) & $5(22.7)$ & $1(11.1)$ & 0.757 \\
\hline Hypertension in pregnancy & $21(16.1)$ & $13(13.1)$ & $5(22.7)$ & $3(33.3)$ & 0.189 \\
\hline Pulmonary Koch's & $2(1.5)$ & $2(2.02)$ & 0 & 0 & 0.250 \\
\hline Others & $3(2.3)$ & $3(3.03)$ & 0 & 0 & 0.071 \\
\hline
\end{tabular}

Based on their RT-PCR testing, 99 (76.1\%) women were covid negative $(\mathrm{CN}), 22(16.9 \%)$ covid positive $(\mathrm{CP})$ and $9(6.9 \%)$ were covid probable (CPro). The baseline characteristics were comparable amongst the three study groups as depicted in table1.

The majority of women were antenatal and in their third trimester. The clinical characteristics of the study subjects are shown in table 2. Fever and breathlessness were the commonest presenting symptoms in all groups. The spectrum of maternal disease ranged from isolated febrile illness to multi-organ dysfunction syndrome (MODS) (figure 1). Isolated febrile illness was the commonest maternal disease in the study groups; severe manifestations like lower respiratory tract infection (LRTI), pulmonary edema and MODS were more common in CPro group. The MODS observed in CPro and $\mathrm{CN}$ group was related to puerperal sepsis whereas covid induced MODS were observed in CP 
The New Indian Journal of OBGYN. 2021 (July-December);8(1)

Table 2: Clinical characteristics in study groups

\begin{tabular}{|c|c|c|c|c|c|}
\hline Parameters & $\begin{array}{l}\text { Total } \\
n=130(\%)\end{array}$ & $\begin{array}{l}\mathrm{CN} \\
\mathrm{n}=99(\%)\end{array}$ & $\begin{array}{l}\text { CP } \\
n=22(\%)\end{array}$ & $\begin{array}{l}\text { CPro } \\
\text { n=9(\%) }\end{array}$ & $\begin{array}{l}P \\
\text { value }\end{array}$ \\
\hline \multicolumn{6}{|l|}{ Clinical presentation } \\
\hline Fever & $100(76.9)$ & $76(76.7)$ & $20(90.0)$ & $4(44.4)$ & 0.020 \\
\hline Breathlessness & $32(24.6)$ & $23(23.2)$ & $6(27.2)$ & $3(33.3)$ & 0.68 \\
\hline Sore throat & $19(14.6)$ & $17(17.1)$ & $2(9.0)$ & 0 & 0.692 \\
\hline Cough & $9(6.9)$ & $6(6.06)$ & $1(4.5)$ & $2(22.2)$ & 0.421 \\
\hline Diarrhoea & $4(3.1)$ & $3(3.03)$ & $1(4.5)$ & 0 & 0.732 \\
\hline Shock & $12(9.2)$ & $11(11.1)$ & 0 & $1(11.1)$ & 0.664 \\
\hline \multicolumn{6}{|l|}{ Vital signs } \\
\hline Temperature & $99.39 \pm 1.34$ & $99.21 \pm 1.19$ & $99.88 \pm 1.68$ & $99.10 \pm 1.15$ & 0.075 \\
\hline Heart rate & $93.61 \pm 11.10$ & $93.50 \pm 21.55$ & $94.04 \pm 12.34$ & $93.27 \pm 11.77$ & 0.992 \\
\hline Respiratory rate & $15.21 \pm 6.16$ & $16.39 \pm 6.14$ & $14.36 \pm 5.00$ & $14.90 \pm 7.34$ & 0.313 \\
\hline Mean oxygen saturation in $\%(\mathrm{SD})$ & $95.39 \pm 5.78$ & $97.51 \pm 3.71$ & $95.68 \pm 5.84$ & $93.00 \pm 7.80$ & 0.018 \\
\hline \multicolumn{6}{|l|}{ Disease severity } \\
\hline Mild & $85(65.3)$ & $67(67.6)$ & $14(63.6)$ & $4(44.4)$ & 0.542 \\
\hline Moderate & $21(16.1)$ & $14(14.1)$ & $5(22.7)$ & $2(22.2)$ & \\
\hline Severe & $24(18.4)$ & $18(18.1)$ & $3(13.6)$ & $3(33.3)$ & \\
\hline \multicolumn{6}{|l|}{ Biochemical parameters } \\
\hline Haemoglobin g/dl Mean(SD) & $9.40 \pm 2.19$ & $9.39 \pm 2.27$ & $9.44 \pm 1.99$ & $9.45 \pm 2.0$ & 0.973 \\
\hline Leukopenia $\leq 4000 / 1$ & $4(3.07)$ & $4(4.04)$ & 0 & 0 & 1.000 \\
\hline Leucocytosis $\geq 15,000 / 1$ & $22(16.9)$ & $15(15.1)$ & $5(22.7)$ & $2(22.2)$ & 0.460 \\
\hline Thrombocytopenia < llacs/1 & $26(20)$ & $24(24.2)$ & $1(4.5)$ & $1(11.1)$ & 0.088 \\
\hline Deranged liver function test & $93(71.5)$ & $67(67.7)$ & $20(90.1)$ & $6(66.6)$ & 0.086 \\
\hline Deranged kidney function test & $22(16.9)$ & $16(16.2)$ & $3(13.6)$ & $3(33.3)$ & 0.380 \\
\hline Abnormal chest $X$ ray & $20(15.3)$ & $12(12.1)$ & $5(22.7)$ & $3(33.3)$ & 0.138 \\
\hline
\end{tabular}

CPro groups suggested significantly lower mean oxygen saturation in CPro women as compared to $\mathrm{CN}$ group ( $\mathrm{CN}$ vs $\mathrm{CPro} \mathrm{p}=0.017$; $\mathrm{CP}$ vs CPro $\mathrm{p}=0.241 ; \mathrm{CN}$ vs CP $\mathrm{p}=0.647$ ). Majority of women had mild disease, although severe disease was more commonly present in CPro group. The chest $\mathrm{X}$ ray changes were more prevalent in CPro group. The commonest chest $\mathrm{X}$ ray finding in the $\mathrm{CN}$ and CPro group was consolidation whereas acute respiratory distress syndrome (ARDS) was a frequent finding in CP group (table 2). The frequency of women requiring oxygen, mechanical ventilation and intensive care unit was more in CPro group (table 3).

Table 3: Maternal outcomes in study groups

\begin{tabular}{|c|c|c|c|c|c|}
\hline Parameters & $\begin{array}{l}\text { Total } \\
n=130(\%)\end{array}$ & $\begin{array}{l}\mathrm{CN} \\
\mathrm{n}=99(\%)\end{array}$ & $\begin{array}{l}\mathrm{CP} \\
n=22(\%)\end{array}$ & $\begin{array}{l}\text { CPro } \\
\text { n=9(\%) }\end{array}$ & $P$ value \\
\hline Oxygen requirement & $41(31.5)$ & $28(28.3)$ & $8(36.3)$ & $5(55.5)$ & 0.209 \\
\hline Mechanical ventilation & $16(12.3)$ & $11(11.1)$ & $3(13.6)$ & $2(22.3)$ & 0.610 \\
\hline ICU admission & $17(13.0 \%)$ & $10(10.10)$ & $4(18.1)$ & $3(33.3)$ & 0.064 \\
\hline Mortality & $21(16.1)$ & $15(15.1)$ & $3(13.6)$ & $3(33.3)$ & 0.343 \\
\hline
\end{tabular}

Overall, there were 21(16.1\%) maternal deaths and the CPro group had maximum mortality. The clinical characteristics and diagnosis in maternal death are shown in table 4. Sepsis with MODS was the commonest cause of maternal death in

$\mathrm{CN}$ group whereas ARDS was the commonest cause of death in CP and CPro groups. The cause of ARDS in CP group was covid disease, whereas it was sepsis in CPro group. Total 103 neonates were there with covid suspect mothers. The neonatal outcomes in the study groups are depicted in table 5. Admission to nursery and neonatal mortality were more in CPro group.

\section{Discussion}

This research provides first ever information on the outcomes of covid probable pregnant women. Previously published data is largely on covid positive individuals, but there is limited information on covid negative and covid probable, which is a grey area requiring further research. During the study period, approximately 3000 women delivered in our hospital and 130 women amongst them presented with covid like symptoms. Out of these women, only 22 were notified to have SARS-CoV-2 infection. CPro group, although very small group as compared to other group. The mean oxygen saturation was significantly less in CPro group. The inter group comparison of $\mathrm{CP}, \mathrm{CN}$ and 
The New Indian Journal of OBGYN. 2021 (July-December);8(1)

\begin{tabular}{|c|c|c|c|c|c|}
\hline Parameters & Total $n=21(\%)$ & $\begin{array}{l}\mathrm{CN} \\
\mathrm{n}=15(\%)\end{array}$ & $\begin{array}{l}\text { CP } \\
n=3(\%)\end{array}$ & $\begin{array}{l}\text { CPro } \\
\text { n=3(\%) }\end{array}$ & P value \\
\hline Mean age, years(SD) & $26.95 \pm 6.72$ & $26.93 \pm 4.87$ & $22.00 \pm 2.83$ & $29.50 \pm 12.48$ & 0.385 \\
\hline Pregnancy status - Antenatal & $6(28.5)$ & $5(33.3)$ & 0 & $1(33.3)$ & \\
\hline -Postnatal & $13(61.9)$ & $8(53.3)$ & $3(100)$ & $2(66.6)$ & 0.765 \\
\hline -Post-abortal & $2(9.5)$ & $2(13.3)$ & 0 & 0 & \\
\hline Comorbidities - Hypertension & $5(23.8)$ & $3(20)$ & $1(33.3)$ & $1(33.3)$ & \\
\hline -Anaemia & $3(14.2)$ & $3(20)$ & 0 & 0 & 1.000 \\
\hline -Others & $4(19.04)$ & $3(20)$ & $1(33.3)$ & 0 & \\
\hline -None & $9(42.8)$ & $6(40)$ & 1(33.3) & $2(66.6)$ & \\
\hline Mean duration of disease in days (SD) & $7.36 \pm 4.39$ & $3.57 \pm 2.74$ & $2.00 \pm 0.00$ & $3.50 \pm 1.29$ & 0.710 \\
\hline Mean duration of hospital stay in days (SD) & $6.94 \pm 8.82$ & $1.62 \pm 2.09$ & $1.50 \pm 0.71$ & $25.50 \pm 47.05$ & 0.559 \\
\hline \multicolumn{6}{|l|}{ Maternal diagnosis } \\
\hline Sepsis with MODS & $10(47.6)$ & $8(53.3)$ & $1(33.3)$ & $1(33.3)$ & 1.000 \\
\hline Pulmonary edema & $4(19.04)$ & $4(26.6)$ & 0 & 0 & 0.705 \\
\hline ARDS & $5(23.8)$ & $1(6.67)$ & $2(66.6)$ & $2(66.6)$ & 0.716 \\
\hline Others(heart disease $\&$ pulmonary emboli) & $2(9.5)$ & $2(13.3)$ & & & 0.545 \\
\hline
\end{tabular}

groups reported maximum morbidity and mortality. Covid testing could not be done in CPro group $(n=9)$ because either the women were very sick on admission or due to prevailing government testing policy at that time.

\begin{tabular}{llllll}
\multicolumn{6}{l}{ Table 5: Neonatal outcomes in the study groups } \\
\hline Parameters & $\begin{array}{l}\text { Total } \\
\mathbf{n = 1 0 3 ( \% )}\end{array}$ & $\begin{array}{l}\mathbf{C N} \\
\mathbf{n}=\mathbf{8 1}(\mathbf{\%})\end{array}$ & $\begin{array}{l}\mathbf{C P} \\
\mathbf{n = 1 7 ( \% )}\end{array}$ & $\begin{array}{l}\mathbf{C P r o} \\
\mathbf{N}=\mathbf{5}(\%)\end{array}$ & $\begin{array}{l}\mathbf{P} \\
\text { value }\end{array}$ \\
\hline Live baby & $87(84.4)$ & $69(85.1)$ & $15(88.2)$ & $3(60)$ & 0.286 \\
\hline $\begin{array}{l}\text { Mode of delivery } \\
\begin{array}{l}\text { Vaginal delivery } \\
\text { Caesarean }\end{array}\end{array}$ & $46(44.6)$ & $31(38.2)$ & $13(76.4)$ & $2(40)$ & 0.015 \\
\hline Mean Birth weight (SD) & $57(55.5)$ & $50(61.7)$ & $4(23.5)$ & $3(60)$ & \\
\hline NICU admission & $2.51 \pm 0.53$ & $2.52 \pm 0.56$ & $2.54 \pm 0.52$ & $2.50 \pm 0.31$ & 0.815 \\
\hline Mean NICU stay in days (SD) & $21(20.3)$ & $15(18.5)$ & $4(23.5)$ & $2(40)$ & 0.481 \\
\hline Neonatal mortality & $16(15.53)$ & $12(4.8)$ & $2(11.7)$ & $2(40)$ & 0.231 \\
\hline
\end{tabular}

different from other groups. There is no study in literature regarding outcomes in CPro group.

Liver function tests derangement was often seen in CP group which is similar to another studies. ${ }^{7,8}$ Kidney function tests were more frequently deranged in $\mathrm{CPro}$ group than $\mathrm{CP}$ or $\mathrm{CN}$ group in our study. A study by Gagilardi et al on covid positive patients reported that deranged kidney function test and acute kidney injury were associated with severe outcomes. ${ }^{9}$

Maternal mortality was seen in $16 \%$ of admitted covid suspect

Majority of the women were antenatal and in their third trimester which was similar to the study by Knigh et al. ${ }^{4}$ The commonest co-morbidities in study population were anaemia, hypertension and pulmonary koch's. Hypertension was seen in one-third of C Pro patients, which was much higher than other groups. In a study by Knigh et al in covid positive pregnant women, $34 \%$ had pre-existing comorbidities. ${ }^{4,5}$ Fever and breathlessness were the most common presenting symptoms which was in concordance with previous studies. ${ }^{6,7}$ The spectrum of maternal disease varied from febrile illness to severe disorder like MODS. CP group more often reported febrile illness, whereas, severe disease like LRTI, pulmonary edema or MODS were frequent in CPro group; however, this difference was not significant statistically. The mean oxygen saturation was significantly lower in CPro group as compared to $\mathrm{CP}$ and $\mathrm{CN}$ groups, suggesting more severe disease in former. Overall, approximately one third of the women had oxygen requirement. The maternal outcomes in the form of need for oxygen, mechanical ventilation and ICU admission were more frequent in CPro group, although not significantly

women. Our being a tertiary care referral hospital, the number of sick patients admitted was high. The maximum mortality was in CPro group (33.3\%) followed by $\mathrm{CN}$ $(15.6 \%)$ and CP $(13.6 \%)$ group, although this difference in frequency was not statistically significant. The mean age of women who died was $26.95 \pm 6.72$ years. Studies have shown the increased risk of severe infection in pregnant and postpartum women. ${ }^{10,11}$ In our study, maximum mortality was observed in postnatal group, which was in accordance to the study by Hantoushzadeh et al. ${ }^{12}$ These women are particularly vulnerable because of the superimposed physiological changes; auto transfusion at the time of delivery and increased vascular resistance following delivery of placenta predispose to worsening of respiratory symptoms. These physiologic changes when overlap with the cytokine upsurge due to covid may attribute to increased mortality in the postnatal period. ${ }^{13,11}$ Nearly $60 \%$ women had co morbidities in the death group. However, the previous study by Hantoushzadeh et al observed no co-morbidities in the case series on maternal death due to covid 19 infection. ${ }^{12}$ Sepsis with MODS was the commonest cause of death in $\mathrm{CN}$ 
The New Indian Journal of OBGYN. 2021 (July-December);8(1)

group whereas ARDS was commonest cause of death in CP and CPro group which indicates that there may be common etiology for the cause of ARDS. Total 103 births occurred during the study period. Live birth frequency was $84.4 \%$ and cesarean rate was high i.e.55\%. This was in concordance to study by Prabhu et al. ${ }^{14}$ The number of neonatal ICU admissions, mean NICU stay and neonatal mortality were more frequent in CPro suggesting more severe disease in this group.

The strength of this study was unbiased inclusion of all obstetric women who presented with covid like symptoms. It provides data of the less studied $\mathrm{CN}$ and CPro groups and comparison with the CP group. The limitation was that being the retrospective study, the necessary follow up could not be done. The variation in the number of women in the three groups was wide.

\section{Conclusion}

In this retrospective study on outcomes of covid suspect, majority of the women who presented with fever or respiratory illness were $\mathrm{CN}$. Although, mild variety of disease was most common in all the groups, however, CPro group had worst maternal and neonatal outcomes. These women could not undergo SARS CoV2 testing due to prevailing local policy at that time. However, prompt testing and initiation of treatment could have redefined the disease course in covid probable group.

\section{Conflict of interest: None. Disclaimer: Nil.}

\section{References}

1. Capobianco G, Saderi L, Aliberti S, Mondoni M, Piana A, Dessole F, et al. COVID-19 in pregnant women: A systematic review and meta-analysis. Eur $\mathrm{J}$ Obstet Gynecol Reprod Biol. 2020 Sep; 252:543-58.

2. Melo GC, Araújo KCGM. COVID-19 infection in pregnant women, preterm delivery, birth weight, and vertical transmission: a systematic review and metaanalysis. Cad Saude Publica. 2020; 36(7): e00087320.

3. Clinical management of COVID 19 by WHO interim guidance may 2020 WHO reference number: $\mathrm{WHO} / 2019-\mathrm{nCoV} / \mathrm{clinical} / 2020.5$. Accessed on 10.12.2020.

4. Knigh M, Bunch K, Simpson N, Gal C, et al. Characteristics and outcomes of pregnant women admitted to hospital with confirmed SARS-CoV-2 infection in UK: national population based cohort study. BMJ. 2020; 369 :m2107.

5. Goyal P, Choi JJ, Pinheiro LC, Schenck EJ, Chen R, Jabri A, et al. Clinical characteristics of Covid-19 in New York City. N Engl J Med. 2020; 382: 2372-4.

6. Pettirosso E, Giles M, Cole S, Rees M. COVID-19 and pregnancy: A review of clinical characteristics, obstetric outcomes and vertical transmission. Aust N Z J Obstet Gynaecol. 2020 Aug 10; 60(5): 640-59

7. Huang C, Wang Y, Li X, Ren L, Zhao J, Hu Y, et al. Clinical features of patients infected with 2019 novel coronavirus in Wuhan, China. Lancet. 2020 Feb 15; 395(10223): 497-506.

8. Chen X, Yang Y, Huang M, et al. Differences between COVID-19 and suspected then confirmed SARS-CoV-2-negative pneumonia: A retrospective study from a single center. J Med Virol. 2020; 92: 1572-79.

9. Gagliardi I, Patella G, Michael A, Serra R, Provenzano M, Andreucci M. COVID-19 and the Kidney: From Epidemiology to Clinical Practice. J Clin Med. 2020 Aug 4; 9(8): 2506.

10. Nakamura-Pereira $M$, Betina Andreucci C, de Oliveira Menezes M, Knobel R, Libertad Soligo Takemoto M. Worldwide maternal deaths due to COVID-19: A brief review. IJOG. 2020 Oct; 151(1): 148-50.

11. Qin C, Zhou L, Hu Z, Zhang S, Yang S, Tao Y, et al. Dysregulation of Immune Response in Patients With Coronavirus 2019 (COVID-19) in Wuhan, China. Clin Infect Dis. 2020 Jul 28; 71(15):762-68.

12. Hantoushzadeh S, Shamshirsaz AA, Aleyasin A, Seferovic MD, Aski SK, Arian SE, et al. Maternal death due to COVID-19. Am J Obstet Gynecol. 2020 Jul; 223(1): 109.e1-109.e16.

13. Chen L, Li Q, Zheng D, Jiang H, Wei Y, Zou L, et al. Clinical characteristics of pregnant women with Covid19 in Wuhan, China. N Engl J Med. 2020; 382: e100.

14. Prabhu M, Cagino K, Matthews KC, Friedlander RL, et al. Pregnancy and postpartum outcomes in a universally tested population for SARS-CoV-2 in New York City: a prospective cohort study. BJOG: an international journal of obstetrics and gynaecology. 127(12):1548-56. 
Bhanu Priya ${ }^{1}$, Sandhya Jain ${ }^{2}$, AG Radhika ${ }^{3}$, Mahendra Kumar ${ }^{4}$, Amita Suneja ${ }^{5}$, Sushil Srivastava ${ }^{6}$

${ }^{1}$ Associate Professor, Department of Obstetrics and Gynaecology, University College of Medical Sciences and Guru Teg Bahadur Hospital, Delhi, India;

${ }^{2}$ Professor, Department of Obstetrics and

Gynaecology, University College of Medical Sciences and Guru Teg Bahadur Hospital, Delhi, India; ${ }^{3}$ Senior Consultant, Department of Obstetrics and

Gynaecology, University College of Medical Sciences and Guru Teg Bahadur Hospital, Delhi, India; ${ }^{4}$ Senior Resident, Department of Obstetrics and Gynaecology, University College of Medical Sciences and Guru Teg Bahadur Hospital, Delhi, India; ${ }^{5}$ Director Professor and Head of the Department of Obstetrics and Gynaecology, University College of Medical Sciences and Guru Teg Bahadur Hospital, Delhi, India;

${ }^{6}$ Associate Professor, Department of Paediatrics, University College of Medical Sciences and Guru Teg Bahadur Hospital, Delhi, India. 